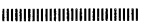

論文

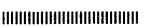

\title{
固相反応によるタンタルホウ化物粉末の合成と焼結
}

\author{
伊藤秀章・佐藤有亮・児玉 諭・中 重治 \\ (名古屋大学工学部人工結晶研究施設, 464-01 名古屋市千種区不老町)
}

\section{Synthesis of Tantalum Boride Powder by Solid State Reaction and Its Sintering}

\author{
Hideaki ITOH, Yusuke SATOH, Satoshi KODAMA and Shigeharu NAKA \\ (Synthetic Crystal Research Laboratory, Faculty of Engineering, Nagoya University, ) \\ Furo-cho, Chikusa-ku, Nagoya-shi 464-01
}

Tantalum boride powders were synthesized by the solid state reaction between tantalum and amorphous boron. Five boride phases $\left(\mathrm{Ta}_{2} \mathrm{~B}, \mathrm{Ta}_{3} \mathrm{~B}_{2}, \mathrm{TaB}, \mathrm{Ta}_{3} \mathrm{~B}_{4}\right.$ and $\left.\mathrm{TaB} \mathrm{B}_{2}\right)$ were formed by heat-treatment of the mixed powders at $1000^{\circ}-1800^{\circ} \mathrm{C}$ for 0-120 min. Formation behavior of these borides was dependent on the heat-treatment temperature, in which structurally stable phases formed in order from low to high temperatures. Single phases of $\mathrm{TaB}_{2}, \mathrm{TaB}$ and $\mathrm{Ta}_{3} \mathrm{~B}_{4}$ were obtained by the heat-treatment of the mixed powders with corresponding stoichiometric compositions at $800^{\circ}, 900^{\circ}$ and $1800^{\circ} \mathrm{C}$, respectively. Sintered compacts of $\mathrm{TaB}$ and $\mathrm{TaB}_{2+x}$ were prepared by a high-pressure sintering of synthesized TaB and TaB $\mathrm{B}_{2+x}$ powders at $4 \mathrm{GPa}$ and $1600^{\circ} \mathrm{C}$ for $15 \mathrm{~min}$. The bulk density of $\mathrm{TaB}$ was $13.51 \mathrm{~g} / \mathrm{cm}^{3}$ (relative density: 95. 1\%) and the Vickers microhardness was $2550 \mathrm{~kg} / \mathrm{mm}^{2}$. The homogeneous range of the solid solution $\mathrm{TaB}_{2+x}$ was $0<x<0.55$, the density and the microhardness of which increased with increasing amount of boron in solid solutions.

[Received August 25, 1989 ; Accepted November 22, 1989]

Key-words : Tantalum boride, Solid state reaction, High pressure sintering, Amorphous boron

\section{1. 緒言}

遷移金属ホウ化物は, 高硬度, 高融点であり, 電気伝 導性に優れているので, 耐摩耗, 耐食材料や電極材料へ の応用が期待されている11 3!。しかしがら，これらの ホウ化物は難焼結性であり，焼結に適した高純度で活性

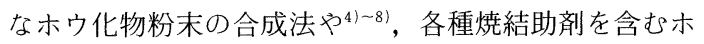
ウ化物の高圧焼結法が開発されている ${ }^{9 \mid \sim 15)}$.

$\mathrm{Ta}$ - B 系では, $\mathrm{T}_{2} \mathrm{~B}, \mathrm{Ta}_{3} \mathrm{~B}_{2}, \mathrm{TaB}, \mathrm{Ta}_{3} \mathrm{~B}_{4}$ 及び $\mathrm{TaB}_{2}$ の5相の存在が確認されている(1),16) 18).この中で, $\mathrm{TaB}$ 及び $\mathrm{TaB}_{2}$ が構造的に比較的安定である. $\mathrm{TaB}$ は斜方 晶系に属し, 融点 $2450^{\circ} \mathrm{C}$, 微小硬度 $\left(H_{\mathrm{v}}\right)$ は 3130 $\mathrm{kg} / \mathrm{mm}^{2}$ であるのに対して, $\mathrm{TaB}_{2}$ は六方晶系で, 比較 的広い固溶範囲をもち, 融点は $3070^{\circ} \mathrm{C}$ と最も高く, 微 小硬度は $2500 \mathrm{~kg} / \mathrm{mm}^{2}$ であると報告されている ${ }^{1), 16 !}$.夕 ンタルホウ化物粉末の固相合成法としては, 金属とホウ 素との直接反応又は金属酸化物の熱還元法などが検討さ れているが91,19) 201，1500 $\mathrm{C}$ 以下の比較的低温における 固相反応による合成に関する研究例は少ない, また, 異 相を含まないホウ化物単相焼結体の性質も明らかにされ ていない.

本研究では, 金属タンタルと非晶質ホウ素との固相反 応により, 各種ホウ化物粉末の合成を行い, とくに
$\mathrm{TaB}, \mathrm{Ta}_{3} \mathrm{~B}_{4}$ と $\mathrm{TaB}_{2}$ の生成過程に注目し，それぞれの 単相粉末を調製した. 固溶体 $\mathrm{TaB}_{2+x}$ については, ホウ 素の固溶範囲を決定した。また， $\mathrm{TaB}$ 及び $\mathrm{TaB}_{2+x}$ 粉 末を超高圧高温下で焼結し，合成粉末の焼結性と焼結体 の密度及び硬度を評価した。

\section{2. 実 験}

\section{1 タンタルホウ化物粉末の合成}

出発原料には, タンタル粉末 (粒径： $5 \sim 10 \mu \mathrm{m}$, 純度 $>$ $99 \mathrm{wt} \%$ ) 及び非晶質ホウ素粉末（粒径：約 $0.9 \mu \mathrm{m}$, 純 度 $>96.6 \mathrm{wt} \%)$ を用いた. それぞれの粉末を単独に真 空中 $\left(5 \times 10^{-5}\right.$ Torr $)$ で $600^{\circ} \mathrm{C}, 60 \mathrm{~min}$ の脱気処理を行っ た. その後, めのう乳鉢で両粉末を所定の配合原子比 $(\mathrm{B} / \mathrm{Ta}=0-3.0)$ になるように混合した. 目的組成の 配合試料を得るために, ホウ素粉末中の正味のホウ素量 を用いて配合組成を決定した。配合試料を真空中で $500^{\circ} \sim 600^{\circ} \mathrm{C}, 60 \mathrm{~min}$ の前処理し，これを窒素気流中で 再混合した. 前処理試料をアルゴン気流中, $650^{\circ}$ $1800^{\circ} \mathrm{C}, 0 \sim 120 \mathrm{~min}$ の加熱処理を行った. $\mathrm{TaB}_{2+x}$ の格 子定数の測定では，合成粉末の均一化のために $1800^{\circ} \mathrm{C}$ $\times 60 \mathrm{~min} の$ 処理後, 粉砕・混合し, 再び $1500^{\circ} \mathrm{C} \times 60$ $\min$ の重複加熱処理を行った. 


\section{2 合成粉末の解析と観察}

処理試料は, 粉末 X線回折法で生成相を同定し, シリ コンを内部標準として, 各相の格子定数を測定し, 相対 強度比 $\left(I / I_{\mathrm{si}}\right)$ によりホウ化物の生成量及び結晶性を 評価した。測定に用いた回折線は, タンタルでは 110 , $\mathrm{Ta}_{2} \mathrm{~B}$ では 211, $\mathrm{Ta}_{3} \mathrm{~B}_{2}$ では $201, \mathrm{TaB}$ では $021, \mathrm{Ta}_{3} \mathrm{~B}_{4}$ では $110, \mathrm{TaB}_{2}$ では 101 であり,これらの回折線高さ をシリコン 200 回折線高さで補正した。また，ICP 発 光分光分析により加熱処理前後の配合比に変化のないこ とを確認した. 処理粉末の粒径, 粒形態は走查型電子顕 微鏡 $(\mathrm{SEM})$ により観察した.

\section{3 焼結体の作製と評価}

合成した単相粉末をガードル型超高圧装置により ${ }^{21)}$, $4 \mathrm{GPa}, 1600^{\circ} \mathrm{C}, 15 \mathrm{~min}$ の条件で焼結した。焼結体の組 織をSEM で観察し, アルキメデス法による密度測定及 びビッカース微小硬度 (200g 荷重) の測定を行った.

\section{3. 結果及び考察}

\section{1 タンタルホウ化物の生成挙動}

タンタルと非晶質ホウ素の配合原子比 $\mathrm{B} / \mathrm{Ta}$ を 0.5 から 2.0 まで変化させて, 各処理温度におけるタンタル ホウ化物の生成過程を調べた. $1000^{\circ} \mathrm{C}, 60 \mathrm{~min}$ の加熱 処理では, 構造的に安定な $\mathrm{TaB}$ 又は $\mathrm{TaB}_{2}$ のみが全組 成範囲で生成し，他の相は生成しなかった，それぞれの 定比組成の混合粉末からは単相のホウ化物粉末が得られ た.

図 1 に, $1400^{\circ} \mathrm{C}, 60 \mathrm{~min}$ の加熱処理を重複して行っ た場合の $\mathrm{B} / \mathrm{Ta}$ と生成相の相対強度との関係を示す. この処理では, $\mathrm{Ta}_{2} \mathrm{~B}, \mathrm{Ta}_{3} \mathrm{~B}_{2}, \mathrm{TaB}, \mathrm{Ta}_{3} \mathrm{~B}_{4}$ 及び $\mathrm{TaB}_{2}$ が 生成した. $\mathrm{B} / \mathrm{Ta}=1.0$ 及び $\mathrm{B} / \mathrm{T} a=2.0$ の配合試料から は, それぞれ化学量論組成の $\mathrm{TaB}$ 及び $\mathrm{TaB}_{2}$ の単相粉 末が得られたが, 他のホウ化物 $\left(\mathrm{Ta}_{2} \mathrm{~B}, \mathrm{Ta}_{3} \mathrm{~B}_{2}\right.$ 及び

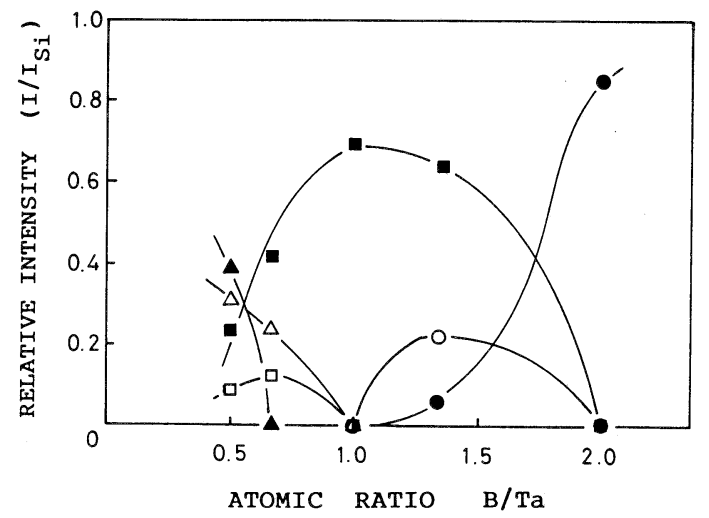

Fig. 1. Relationship between the relative intensity of tantalum boride and the atomic ratio $\mathrm{B} / \mathrm{Ta}$.

Treatment conditions : $\left(1400^{\circ} \mathrm{C} \times 60 \mathrm{~min}\right) \times 2$,

$\triangle: \mathrm{Ta}, \boldsymbol{\Delta}: \mathrm{Ta}_{2} \mathrm{~B}, \square: \mathrm{Ta}_{3} \mathrm{~B}_{2}, \mathbf{\square}: \mathrm{TaB}, \bigcirc: \mathrm{Ta}_{3} \mathrm{~B}_{4}$, $: \mathrm{TaB}_{2}$

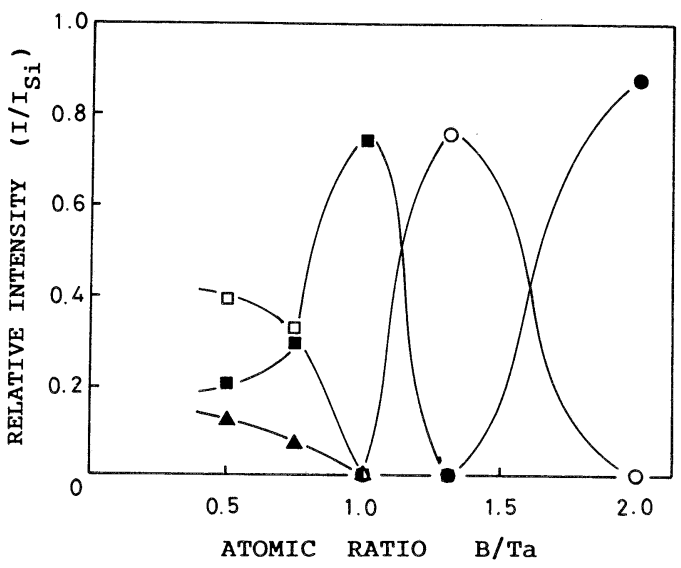

Fig. 2. Relationship between the relative intensity of tantalum boride and the atomic ratio $\mathrm{B} / \mathrm{Ta}$.

Treatment conditions $: 1800^{\circ} \mathrm{C} \times 60 \mathrm{~min}, \boldsymbol{\Delta}: \mathrm{Ta}_{2} \mathrm{~B}$, $\square: \mathrm{Ta}_{3} \mathrm{~B}_{2}, \boldsymbol{\square}: \mathrm{TaB}, \bigcirc: \mathrm{Ta}_{3} \mathrm{~B}_{4}, \bigcirc: \mathrm{TaB}_{2}$

$\left.\mathrm{Ta}_{3} \mathrm{~B}_{4}\right)$ は単相としては得られなかった。

図 2 に, $1800^{\circ} \mathrm{C}, 60 \mathrm{~min}$ の加熱処理を行った場合に おける $\mathrm{B} / \mathrm{Ta}$ と生成相の相対強度との関係を示す. $1400^{\circ} \mathrm{C}$ でのホウ化物の生成挙動と類似しているが, $\mathrm{Ta}_{3} \mathrm{~B}_{4}$ の相対強度が強く, 定比組成試料からは単相粉末 が得られた.

以上の結果から，各配合組成におけるタンタルホウ化 物の生成挙動は, 大きな処理温度依存性を示し, 構造的 に安定な相が低温から高温の順に生成する.この傾向は, 同様の固相反応によるニオブホウ化物の生成挙動 ${ }^{6}$ とよ く似ている.

\section{2 単相粉末の生成に及ぼす加熱処理温度の影響}

$1800^{\circ} \mathrm{C}$ の加熱処理で単相粉末が得られた $\mathrm{TaB}$, $\mathrm{Ta}_{3} \mathrm{~B}_{4}$ 及び $\mathrm{TaB}_{2}$ にそれぞれ対応する定比組成試料 $\mathrm{B} / \mathrm{Ta}=1.0,1.3$ 及び 2.0 の配合粉末について, 加熱処

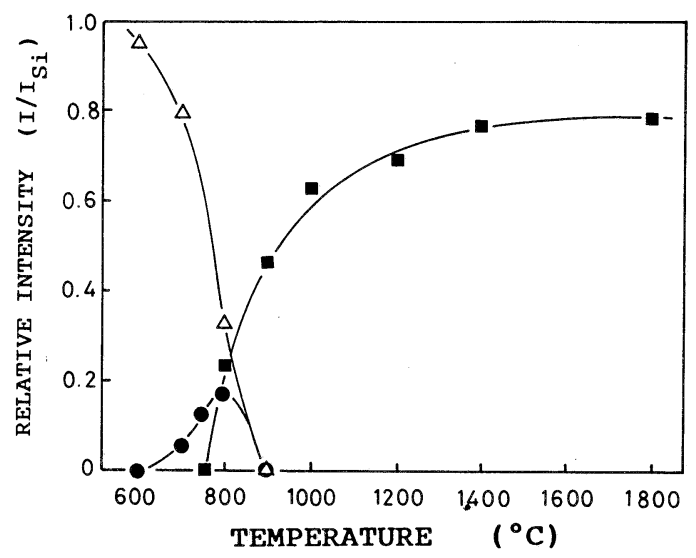

Fig. 3. Variations of relative intensity of formed species as a function of treatment temperature.

Starting powder composition $: \mathrm{B} / \mathrm{Ta}=1.0$, Treatment time $: 60 \mathrm{~min}, \triangle: \mathrm{Ta}, \square: \mathrm{TaB}, \bigcirc: \mathrm{TaB}_{2}$ 


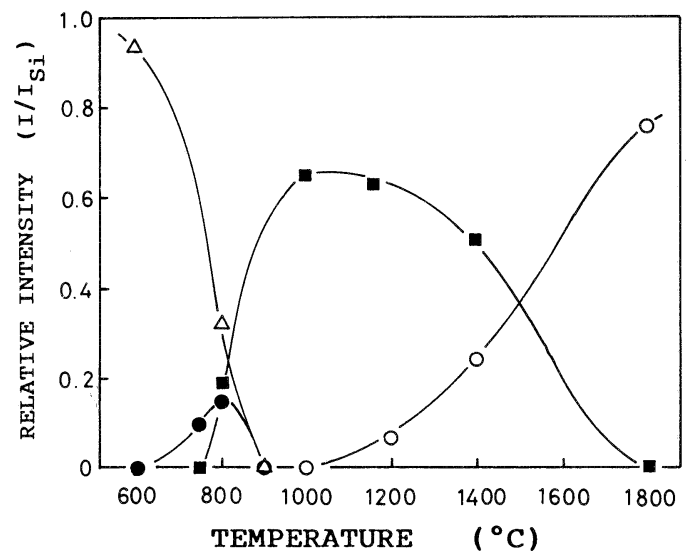

Fig. 4. Variations of relative intensity of formed species as a function of treatment temperature.

Starting powder composition: $\mathrm{B} / \mathrm{Ta}=1.3$,

Treatment time: $60 \mathrm{~min}$,

$\triangle: \mathrm{Ta}, \square: \mathrm{TaB}, \bigcirc: \mathrm{Ta}_{3} \mathrm{~B}_{4}, \bigcirc: \mathrm{TaB}_{2}$

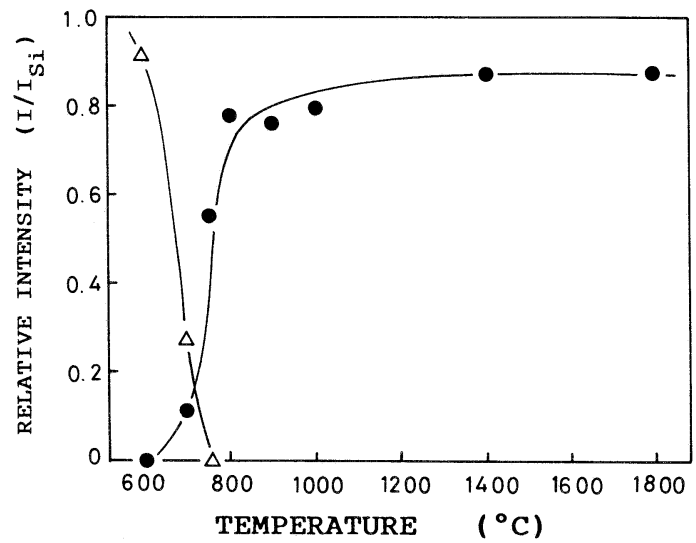

Fig. 5. Variations of relative intensity of formed species as a function of treatment temperature.

Starting powder composition $: \mathrm{B} / \mathrm{Ta}=2.0$, Treatment time : $60 \mathrm{~min}, \triangle: \mathrm{Ta}, \mathrm{T}: \mathrm{TaB}_{2}$

理温度の影響を調べた。なお，加熱処理時間の生成相に 及ぼす影響は，60～120 min の範囲では比較的小さかっ

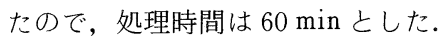

図 3 に, 配合原子比 $\mathrm{B} / \mathrm{Ta}=1.0$ の組成試料を $600^{\circ} \sim$ $1800^{\circ} \mathrm{C}, 60 \mathrm{~min}$ の条件で加熱処理した場合の処理温度 と生成相の相対強度との関係を示す. $600^{\circ} \mathrm{C}$ では夕ン夕 ルの回折線のみが観察された. $700^{\circ} \mathrm{C}$ では $\mathrm{TaB}_{2}$ の生成 を認め, 処理温度の上昇とともにタンタルの相対強度が 減少して $\mathrm{TaB}_{2}$ の生成量が増大した。 $800^{\circ} \mathrm{C}$ 以上では $\mathrm{TaB}$ が生成して, $\mathrm{TaB}_{2}$ の相対強度が減少し, $900^{\circ} \mathrm{C} て ゙$ $\mathrm{TaB}$ のみの結晶相が得られた. $900^{\circ} \mathrm{C}$ より高温で, $\mathrm{TaB}$ の相対強度が徐々に増大し結晶性が向上するが, $1400^{\circ} \mathrm{C}$ 以上では飽和した。

図 4 に, $\mathrm{B} / \mathrm{Ta}=1.3$ の場合の処理温度と生成相の相 対強度との関係を示す. $750^{\circ} \mathrm{C}$ で $\mathrm{TaB}_{2}, 800^{\circ} \mathrm{C}$ で $\mathrm{TaB}$
が生成した後, $1200^{\circ} \mathrm{C}$ から $\mathrm{Ta}_{3} \mathrm{~B}_{4}$ が生成を開始し, 処 理温度の上昇とともに $\mathrm{TaB}$ の相対強度が減少して $\mathrm{Ta}_{3} \mathrm{~B}_{4}$ の相対強度が増大した。 $\mathrm{Ta}_{3} \mathrm{~B}_{4}$ のみの結晶相を得 るには， $1800^{\circ} \mathrm{C}$ の高温処理が必要であった。

図 5 に, $\mathrm{B} / \mathrm{Ta}=2.0$ の場合の処理温度と生成相の相 対強度との関係を示す。 $\mathrm{TaB}_{2}$ の生成開始温度は, $700^{\circ} \mathrm{C}$ であり，処理温度の上昇とともにタンタルの相対 強度が減少して $\mathrm{TaB}_{2}$ の相対強度が増大し， $750^{\circ} \mathrm{C}$ で既 に $\mathrm{TaB}_{2}$ 単相となった。

図3〜 5 から明らかなように, $650^{\circ} \sim 800^{\circ} \mathrm{C}$ の低温域 ではいずれの配合組成でも $\mathrm{TaB}_{2}$ が生成するが，高温に なるにつれて $\mathrm{TaB}$ 又は $\mathrm{Ta}_{3} \mathrm{~B}_{4}$ などの配合組成に対応し た単相の定比化合物が生成することが分かる。このよう にタンタルホウ化物の中でホウ素含有量の最も多い化合 物である $\mathrm{TaB}_{2}$ が比較的低温で生成するのは，他の遷移 金属ホウ化物の場合と同様に ${ }^{2), 3), 10)}$ ，二木ウ化物の高い 安定性によるものであろう.

\section{3. $3 \mathrm{TaB}_{2+x}$ 固溶体の均一領域}

二ホウ化タンタルはホウ素原子の比較的広い固溶範囲 をもつことが知られているので，配合原子比を $\mathrm{B} / \mathrm{Ta}=$ 1.9 2. 9 と変化させて，格子定数を測定した．図 6 に, $1500^{\circ} \mathrm{C}, 60 \min \times 2$ 回の処理条件における配合組成之 $a$ 軸及び $c$ 軸の格子定数の值との関係を示す．格子定数 は, $\mathrm{B} / \mathrm{Ta}=2.0$ 以上で直線的に変化し, $\mathrm{TaB}_{2+x}$ 固溶体 の均一領域は $x=0 \sim 0.55$ と推定される. 文献値 ${ }^{16)}$, 18) 20) と比較すると上限はほぼ一致する。しかし，下限につい ては文献值では $1.5 \sim 1.8$ とタンタル過剩側になってい るが，本実験ではタンタル過剩側には均一領域が認めら

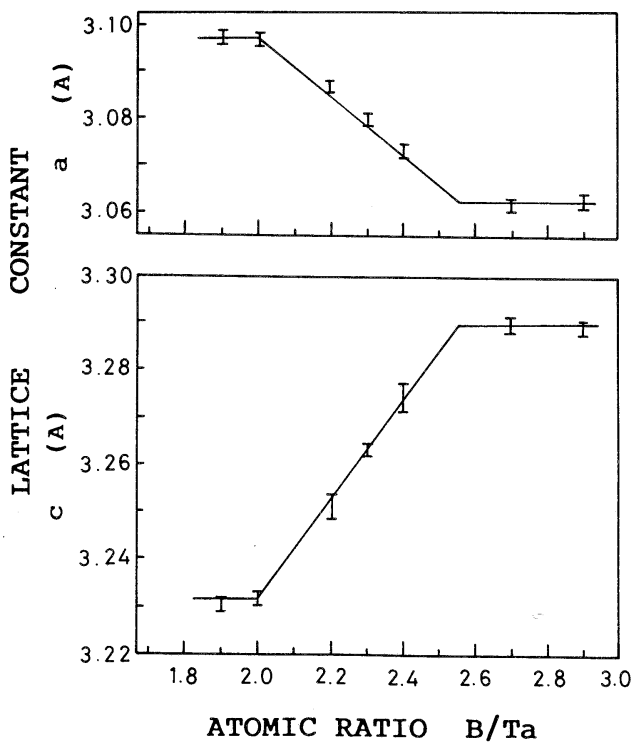

Fig. 6. Lattice constant of the synthesized $\mathrm{TaB}_{2+x}$ powder vs. the atomic ratio $(\mathrm{B} / \mathrm{Ta})$ of starting powder. Treatment conditions : $\left(1500^{\circ} \mathrm{C} \times 60 \mathrm{~min}\right) \times 2$ 

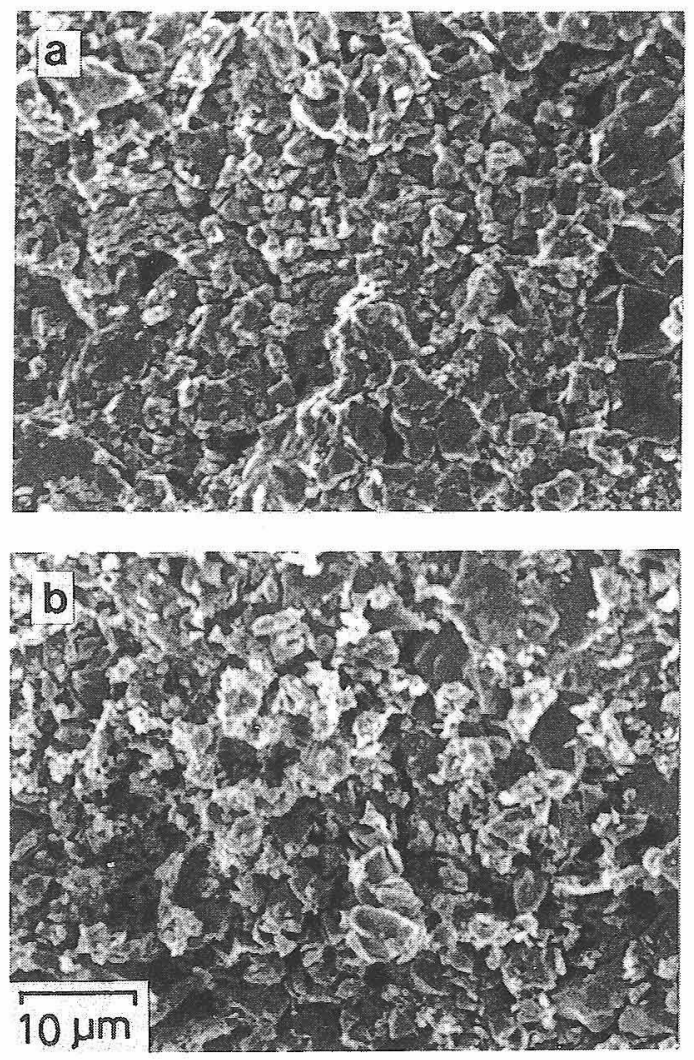

Fig. 7. SEM of the fractured surface of the $\mathrm{TaB}_{2+x}$ compacts sintered at $4 \mathrm{GPa}$ and $1600^{\circ} \mathrm{C}$ for $15 \mathrm{~min}$. (a) $\mathrm{B} / \mathrm{Ta}=2.0$, (b) $\mathrm{B} / \mathrm{Ta}=2.3$. Synthetic conditions of the $\mathrm{TaB}_{2+x}$ powder : $\left(1500^{\circ} \mathrm{C} \times 60 \mathrm{~min}\right) \times 2$

れない。また，均一領域下限の格子定数は， $a=3.097$ $\AA, c=3.232 \AA$ であり, 上限のそれは $a=3.063 \AA, c=$ $3.289 \AA$ と推定された.これらの值は文献值 ${ }^{191-201,221}$ 亡ほ ば一致する。図から，固溶範囲内では配合原子比が増加 すると $a$ 軸の長さは娍少し, $c$ 軸の長さは増加するこ とが明らかである。これは, 化学量論組成の $\mathrm{TaB}_{2}$ は六 方晶であるので，過剰のホウ素原子は結晶格子の $(0$, $0,1 / 2)$ 位置に侵入し, 固溶体を形成することを示唆し ている ${ }^{31,19)}$.

\section{4 合成 $\mathrm{TaB}$ 及び $\mathrm{TaB}_{2+x}$ 粉末の焼結性}

合成した $\mathrm{TaB}$ 及び $\mathrm{TaB}_{2+x}$ 単相粉末の粒径及び粒形 態は，いずれも原料タンタル粉末とほぼ同一であり，凝 集や粒成長は観察されなかった。金属タンタルへのホウ 素の拡散によりホウ化物が生成したものと推察される.

単相の合成 $\mathrm{TaB}$ 粉末 (a), 及びホウ素 $10 \mathrm{~mol} \%$ 過 剩組成で合成した粉末 $(\mathrm{TaB}+0.1 \mathrm{~B})$ にタンタル金属 粉末を $10 \mathrm{~mol} \%$ 添加・混合した $(\mathrm{TaB}+0.1 \mathrm{~B})+0.1$ $\mathrm{Ta}$ の組成の調製粉末 (b) をそれぞれ $4 \mathrm{GPa}, 1600^{\circ} \mathrm{C}$, $15 \min の$ 条件で $\mathrm{TaB}$ 単相焼結体を作製した。（a）試 料の焼結体に比べて，（b ）試料では気孔が少なく密度 は $13.51 \mathrm{~g} / \mathrm{cm}^{3}$ (相対密度 : $95.1 \%$ ), 微小硬度は 2550 $\mathrm{kg} / \mathrm{mm}^{2}$ であった。焼結体のX線回折では，タンタルは 検出されず $\mathrm{T} \mathrm{aB}$ のみ回折線が認められた。遊離非晶 質ホウ素と添加タンタルとの反応焼結により緻密化が助 長されたものと考えられる柿。

図 7 に, $\mathrm{B} / \mathrm{Ta}=2.0$ 及び $\mathrm{B} / \mathrm{Ta}=2.3$ の配合組成から 得られた $\mathrm{TaB}_{2+x}$ 固溶体粉末を同条件 $\left(4 \mathrm{GPa}, 1600^{\circ} \mathrm{C}\right.$, $15 \mathrm{~min}$ ) で超高圧焼結した場合の焼結体破面の SEM 写 真を示す，異常粒成長は観察されず均一な組織である。 化学量論組成の $\mathrm{TaB}_{2}$ 焼結体の密度及び微小硬度は, そ れぞれ $10.64 \mathrm{~g} / \mathrm{cm}^{3}$ 及び $1050 \mathrm{~kg} / \mathrm{mm}^{2}$ であり，ホウ素 の固溶度が増加するにつれて，密度と硬度が大きくなる 傾向を示した。ここは，前述のようにホウ素原子が過剩 に存在すると，ホウ素原子の平面網目構造が強固になり 硬度が増加したためであろう181,191. しかし，これらの単 相焼結体の相対密度は 85〜90\% とまだ低いので, 硬度 及び鞁性の向上には焼結密度を高くするために，より微 細なホウ化物粉末の合成法や焼結条件の改善が必要であ る.

\section{4. 総 括}

金属タンタルと非晶質ホウ素との固相反応により，夕 ンタルホウ化物粉木を合成し, 単相の合成粉末を超高圧 下で焼結し，次つ結論を得た。

(1) $1000^{\circ} \sim 1800^{\circ} \mathrm{C}, 60 \min$ の固相反応により, $\mathrm{Ta}_{2} \mathrm{~B}, \mathrm{Ta}_{3} \mathrm{~B}_{2}, \mathrm{TaB}, \mathrm{Ta}_{3} \mathrm{~B}_{4}, \mathrm{TaB}_{2}$ が生成する。各組成 の木ウ化物の生成挙動は，大きな加熱処理温度依存性を 示し,構造的に安定な相が低温から高温の順に生成する。

(2) 単相の $\mathrm{TaB}_{2}, \mathrm{TaB}$ 及び $\mathrm{Ta}_{3} \mathrm{~B}_{4}$ 粉末は, それぞ れの定比組成配合試料を $800^{\circ} \mathrm{C}, 900^{\circ} \mathrm{C}$ 及び $1800^{\circ} \mathrm{C}$ で 加熱処理することによって得られる. また, $\mathrm{TaB}_{2+x}$ 固 溶体のホウ素の固溶範囲は $0<x<0.55$ であった。

(3) 合成した $\mathrm{TaB}$ 粉末を, $4 \mathrm{GPa}, 1600^{\circ} \mathrm{C}, 15 \mathrm{~min}$ の条件で超高圧焼結した結果, 密度 $13.51 \mathrm{~g} / \mathrm{cm}^{3}$ (相対 密度: $95.1 \%$ ), 微小硬度 $2550 \mathrm{~kg} / \mathrm{mm}^{2}$ の $\mathrm{TaB}$ 単相焼 結体が得られた。 $\mathrm{TaB}_{2+x}$ 固溶体を同条件で焼結すると， ホウ素の固溶度の増加につれて密度と微小硬度の值が増 加した。

\section{文献}

1) G.V. Samsonov and I. M. Minitskii, "Handbook of Refractory Compounds", IFI/Plenum (1980).

2) V.I. Matkovich, Ed., "Boron and Refractory Boride", Springer-Verlarg (1977) pp. 351-76.

3) 中野喜久男, セラミックス, 24, 500-08 (1989).

4) T. Matsudaira, H. Itoh, S. Naka, H. Hamamoto and M. Obayashi, J. Mater. Sci., 23, 288-92 (1988).

5) H. Itoh, T. Matsudaira, S. Naka and H. Hamamoto, $J$ Mater. Sci., 24, 420-24 (1989).

6) T. Matsudaira, H. Itoh, S. Naka and H. Hamamoto, $J$. Less-Common Metals, 115, 207-14 (1989).

7) H. Itoh, T. Matsudaira, S. Naka, H. Hamamoto and M. Obayashi, J. Mater. Sci., 22, 2811-15 (1987). 
8) 浜本 弘, 大林幹男, 松平恒昭, 伊藤秀章, 中 重治, 粉体および粉末治金, 35, 128-30 (1988).

9) V.I. Matkovich Ed., "Boron and Refractory Boride", Springer-Verlarg (1977) pp.457-93.

10）渡辺忠彦, 徳永洋一, 日本金属学会会報, 25, 1018-25 (1986).

11）渡辺忠彦，粉体および粉末冶金，36，365-70（1989）.

12) 酒井恒蔵, セラミックス, 24, 526-32 (1989).

13）西川 洋, セラミックス, 22, 40-45 (1987).

14）宮本欽生, 上條栄治, 小泉光恵, 粉末および粉末治金, 34, 101-06 (1987).

15）小田原 修, セラミックス, 24, 509-14 (1989).

16) H. Nowotny, F. Benesovsky and R. Kieffer, $Z$.
Metallk., 50, 417-23 (1959).

17) T.B. Massalski, "Binary Alloy Phase Diagram", Am. Soc. Metals (1986) p. 386.

18）エル・ベ・カテリニコフ，エヌ・エヌ・バシルイコフ, ゼ・ゲ・ガリアクバロフ,ア・イ・カシタノフ, “超硬融 点材料便覧”, 日ソ通信社 (1969) pp. 209-11.

19) R. Kiessling, Acta Chem. Scand. , 3, 603-15 (1949).

20) L. Brewer, D. L. Sawyer, D. H. Templeton and C. H. Dauben, J. Am. Ceram. Soc., 34, 173-79 (1951).

21）松平恒昭, 伊藤秀章, 中 重治, 浜本 弘, 大林幹男, 窯協, 95，248-52（1987）.

22）岡田 繁, 阿刀田徹三, 高橋保夫, 日化, 1535-43 (1985). 